\title{
Effect of thermal annealing on the structural and thermoelectric propertiesof electrodeposited antimony telluride thin films
}

\author{
NaokiHatsuta, DaichiTakemori, Masayuki Takashiri ${ }^{*}$ \\ Department of Materials Science, Tokai University, 4-1-1 Kitakaname, Hiratsuka, Kanagawa 259-1292, Japan
}

\begin{abstract}
We investigated the effect of thermal annealing on structural and thermoelectric properties of p-type antimony telluride $\left(\mathrm{Sb}_{2} \mathrm{Te}_{3}\right)$ thin filmsfabricated on a stainless steel (SUS304) substrate by electrodeposition.Antimony telluride thin films were annealed for $1 \mathrm{~h}$ at temperatures between 200 and
\end{abstract} $400^{\circ} \mathrm{C}$. We observed that the as-deposited thin film and thin films annealed at temperatures less than $250^{\circ} \mathrm{C}$ possessed a stoichiometric atomic composition $(\mathrm{Sb}: \mathrm{Te}=40: 60)$ with no impurities from the substrate. At the annealing temperature of $300^{\circ} \mathrm{C}$,we observed a certain amount of impurities $(\mathrm{Fe}, \mathrm{Cr}$, $\mathrm{Ni})$ in the thin film. The Seebeck coefficient was decreased but the electrical conductivity was increased for films treated at $300^{\circ} \mathrm{C}$. As a result, the thin film exhibited a maximum power factor of 13.6 $\mu \mathrm{W} /\left(\mathrm{cm} \cdot \mathrm{K}^{2}\right)$. Onfurther increasing the annealing temperature to $400^{\circ} \mathrm{C}$, the film structure and thermoelectric properties were drastically changed. The impurity concentration in the thin film reached approximately 50 at $\%$. The crystal structure of $\mathrm{Sb}_{2} \mathrm{Te}_{3}$ completely disappeared, and instead, other chemical compoundsformed byalloying the elements of the thin film and the substrate were observed. 
Keywords: Electrodeposition; Antimony telluride; Thermoelectric; Thermal annealing;Thin films

*Author to whom correspondence should be addressed. Electronic mail: takashiri@ tokai-u.jp (M.

Takashiri). 


\section{Introduction}

Recently, thermoelectric materials have attracted considerable interest because of developmentsinenergy harvesting technology. These materialsare able to covert thermal energy into electric energy, and vice versa convert electricity into heat. In particular, thermoelectric generators produce electric power from thermal energyfor a variety of usesfor mobile and wireless electronics[1-3].Commercial applications of thermoelectric generators require high energy conversion efficiency, miniaturization, and low manufacturing costs.

The energy conversion efficiency, i.e., thermoelectric performance, is dependent on a dimensionless figure of merit (ZT), which is defined as $Z T=\sigma S^{2} T / \kappa$, where $\sigma$ is the electrical conductivity, $S$ is the Seebeck coefficient, $T$ is the absolute temperature, and $k$ is the thermal conductivity. To improve the thermoelectric performance, the power factor, $\sigma S^{2}$, should be maximized and the thermal conductivity should be minimized.Regardingthe chemical composition of thermoelectric materials, bismuth telluride $\left(\mathrm{Bi}_{2} \mathrm{Te}_{3}\right)$ and similarly structured materials with the $R 3 m-D_{3 d}^{5}$ space group, such as antimony telluride $\left(\mathrm{Sb}_{2} \mathrm{Te}_{3}\right)$ and bismuth selenium $\left(\mathrm{Bi}_{2} \mathrm{Se}_{3}\right)$,are the most suitable materials[4].This is because these materials exhibit the highestZT near room temperature (RT), providing many energy harvesting applications. In general, thermoelectric generators consist of n-type (e.g. bismuth telluride) and p-type (e.g. antimony telluride) thermoelectric materials.

Thin film technology is beneficial from the viewpoint of miniaturization as well as the low manufacturing cost of thermoelectric generators. The advantage of thin film technology is that it allows 
for deposition ofthin films over a large area at once and fabrication of fine structures. In addition, this technology makes it relatively easy to control the crystal growth and atomic composition of the materials.To date, there are many reports ofthin film thermoelectric generators produced using various conventionaldeposition methods, including evaporation[5-7], sputtering[8-10], and electrodeposition[11-13].Among these deposition methods, electrodeposition is one of the most favorable because it is very costeffective; this is because of its easy scalability, high deposition rate, and the fact that it involves operation at low temperature with no requirement for vacuum conditions.

Electrodeposited bismuthtelluride-basedalloy thin films were first fabricated byTakahashi et al.[14].They fabricated the thin films using an aqueous solution of $\mathrm{pH} 0.9$ containingvarious $\mathrm{Bi}\left(\mathrm{NO}_{3}\right)_{3}$ concentrations and a constant $\mathrm{TeO}_{2}$ concentration $(1.50 \mathrm{mM})$ on a $\mathrm{Ti}$ sheet. Martin-Gonzalez et al.performed asystematic investigation of the electrochemical reactions andcompositional changes as a function of applied potential[15].Since then, research inbismuth telluride-basedalloy thin filmsformed by electrodeposition has received much attention owing totheimprovement in thermoelectric properties undertheestablished experimental conditions[16-18].To further improve the thermoelectric performance, deposited filmsmust be subjected to additional treatment such as thermal annealing[9,19],electron beam irradiation[20-22], and pulsed laser annealing[23,24].In particular, thermal annealing is well investigated in bismuth telluride-based alloy thin films, and has been demonstrated to greatly improve thermoelectric properties[25-27].However, not much is known about the effects of thermal annealing for electrodeposited bismuth telluride-based alloy thin films, especially p-type thin 
films[28-30].Additionally, impurity diffusion from the substrateinto the deposited film during thermal annealing has not been well investigated[31].

In this study, we investigated the effect of thermal annealing on structural and thermoelectric properties of p-type antimony telluride thin filmsprepared by electrodeposition. The thin films were formed onstainless steel (SUS304) substrates, followed bythermal annealing under an inert gas atmosphere. The structural properties of the treated thin films were characterized in terms of theirsurface morphology, atomic composition, and crystallographic structure.The in-plane thermoelectric properties were measured at RT.Finally, we discuss the relationship between annealing temperature and the various film properties, and the impurities in the thin films.

\section{Experimental section}

Prior to the electrodeposition, cyclic voltammetry (CV)was performed with a standard three-electrode cell (HSV-110; HOKUTO) in an unstirred electrolytesolution consisting of $1.3 \mathrm{mMSbF}_{3}, 1.6 \mathrm{mMTeO}_{2}$, and $0.39 \mathrm{M}$ hydrochloric acid diluted by deionized water. The electrolytetemperature was maintained at RT.The CV scan rate was fixed at $5 \mathrm{mV} / \mathrm{s}$. The working electrode (electrode area: $1.5 \mathrm{~cm}^{2}$ ) wasa stainless steel (SUS304) substrate with $80 \mu \mathrm{m}$ thickness, chosen because ofits excellent corrosion resistance. A platinum-coated titanium mesh on a titanium plate was used as the counter electrode (electrode area: $1.5 \mathrm{~cm}^{2}$ ). $\mathrm{A} \mathrm{Ag} / \mathrm{AgCl}$ (saturated $\mathrm{KCl}$ ) electrode was used as the reference electrode.

Antimony telluride thin films were prepared by potentiostatic electrodeposition using a standard 
three-electrode cell.The conditions of the electrodes were the same as those of the CV analysis. The working and counter electrodes were degreased using a sodium hydroxide and a hydrochloric acid solution, and then washed with deionized water. The thin film deposition wasperformedwhile stirring at $200 \mathrm{rpm}$ at RT. The constituents of the electrolytewere the same as that of the CV analysis. The electrode voltage was set at $-0.1 \mathrm{~V}$ using a potentiostat/galvanostat (HA-151B, Hokuto Denko). We measured the film thickness by two methods, which are cross-section SEM images and mass difference between the initial substrate and the film deposited substrate. We observed that the film thickness was mostly uniform, and the two methods exhibited mostly the same thickness. As a result, the electrochemically deposited films had an average thickness of approximately $300 \mathrm{~nm}$.

To thermally annealthe antimony telluride thin films, the samples were placed in an electric furnace, evacuated to $1.0 \mathrm{~Pa}$ and then purged five times with mixed gas (argon $95 \%$ and hydrogen $5 \%$ ). The furnace was then filled with the same mixed gas at atmospheric pressure, under a gas flow rate of 1.0 SLM throughout the thermal annealing process. Temperatures were increased from 200 to $400^{\circ} \mathrm{C}$ at a rate of $4 \mathrm{~K} / \mathrm{min}$ and the samples were maintained at themaximum temperature for $1 \mathrm{~h}$. After thermal annealing, the samples were cooled to RTnaturally in the furnace.To avoid complicationsin analysis due to the electrical conduction of the stainless steel substrate, the film was fixed on a glass plate using an epoxy resin, followed by thin film removal from the substrate.

Surface morphologies of the antimony telluride thin films were examined using a scanning electron microscope (SEM; JSM-6301F, JEOL). Atomic compositions weremeasured by an electron probe 
microanalyzer(EPMA;EPMA-1610, Shimadzu). The crystallographic properties were evaluated by X-ray diffraction (XRD; Mini Flex 600, Rigaku) using the $\mathrm{Cu}-\mathrm{K}_{\alpha}$ line $(\lambda=0.154 \mathrm{~nm})$.

The in-plane Seebeck coefficient, $S$,of the antimony telluride thin filmswas measured at RT. One end of the thin film was connected to a heat sink and the other end to a heat source. The Seebeck coefficient was determined as the ratio of the potential difference along the film between the different temperatures.Temperatures were measured with two $0.1 \mathrm{~mm}$ diameter K-type thermocouples pressed onto the thin films. The distance between the thermocouples was $13 \mathrm{~mm}$. The in-plane electrical conductivity, $\sigma$, of the thin films was also measured at RTby a four-point probe method (RT-70V, NAPSON). The in-plane power factor, $S^{2} \sigma$, was calculated from the measured Seebeck coefficient and electrical conductivity.

\section{Results and discussion}

\subsection{Cyclic voltammetryanalysis}

To determine the appropriate potential range for depositing anantimony telluride film, CV analysis using anelectrolyte consisting of $1.3 \mathrm{mM} \mathrm{SbF}_{3}, 1.6 \mathrm{mM} \mathrm{TeO}_{2}$, and $0.39 \mathrm{M}$ hydrochloric acid was performed, as shown in Fig. 1.The cyclic voltammogram revealed two cathodic peaks at potentials of approximately -0.1 and $-0.2 \mathrm{~V}$ vs $\mathrm{Ag} / \mathrm{AgCl}$, which may be attributed to the electrodeposition of $\mathrm{Te}$ and $\mathrm{Sb}$, respectively[32].The overall antimony telluride $\left(\mathrm{Sb}_{2} \mathrm{Te}_{3}\right)$ deposition reaction can be described as follows[33]: 


$$
2 \mathrm{SbO}^{+}+3 \mathrm{HTeO}_{2}^{+}+13 \mathrm{H}^{+}+18 \mathrm{e}^{-} \rightarrow \mathrm{Sb}_{2} \mathrm{Te}_{3}+8 \mathrm{H}_{2} \mathrm{O}
$$

Based on the obtained cyclic voltammogram, it is apparent that the appropriate applied potential for the deposition of antimony telluride thin films is in the range of -0.1 to $-0.2 \mathrm{~V}$. We set the applied potential to $-0.1 \mathrm{~V}$ vs $\mathrm{Ag} / \mathrm{AgCl}$.

\subsection{Structural properties of antimony telluride thin films}

SEM images in Fig. 2 show that the surface morphologies of electrodeposited antimony telluride films arestrongly affected by annealing temperature. In Fig. 2(a), we observe that the as-deposited film is covered with nearly spherical grainsof smooth surface, and agrain size of approximately $1 \mu \mathrm{m}$. When the thin film is annealed at $200^{\circ} \mathrm{C}$, the shape of grains remainsunchanged,butthe grain size increases to approximately $2 \mu \mathrm{m}$ (Fig. 2(b)). The shape of the grains and grain size of the thin film annealed at $250^{\circ} \mathrm{C}$ are almost the same as those of the thin film annealed at $200^{\circ} \mathrm{C}$ (Fig. 2(c)). At the annealing temperature of $300^{\circ} \mathrm{C}$, the grain size remainsunchanged from that of the thin film at $250^{\circ} \mathrm{C}$, but the grain surface becomes confetti-like (Fig. 2(d)). The surface of the thin film annealed at $350^{\circ} \mathrm{C}$ seems to have needle-shaped crystals growing on the spherical grains, and the space between grains increased (Fig. 2(e)). Furthermore, when the annealing temperature increases to $400^{\circ} \mathrm{C}$, the surface morphology drastically changes (Fig. 2(f)). Thethin film exhibits a porous structure with irregular-shaped submicrongrains.

The dependence of atomic composition on annealing temperature and the impurities coming from the 
SUS304 stainless steel substrate (Fe:Cr:Ni $=70: 19: 9)$ is shown in Fig. 3(a). It is noted that EMPA measurement was performed after the thin filmswere removed from the substrates. The as-deposited thin film data is plotted at $27^{\circ} \mathrm{C}$. The as-deposited film and the film annealed at $200^{\circ} \mathrm{C}$ exhibit stoichiometric atomic composition $(\mathrm{Sb}: \mathrm{Te}=40: 60)$, and contamination from the substrate is not observed. When the annealing temperature is increased to $250^{\circ} \mathrm{C}$, the atomic composition of tellurium and antimony decrease, and small amounts of iron and chromium can be seen. This indicates that the elements in the substrate gradually diffuse into the thin film with increasing annealing temperature. Furtherincreasing the annealing temperature to $300^{\circ} \mathrm{C}$ shows that the atomic composition of tellurium and antimony continues to decrease, and $\mathrm{Fe}, \mathrm{Cr}$, and $\mathrm{Ni}$ impurities are detected. In particular, the atomic composition of Fereaches approximately $13 \mathrm{at} \%$. Finally, the thin film annealed at $400^{\circ} \mathrm{Chas}$ a significantly increasedquantity of impurities. The total atomic composition of impurities from the substrate reaches approximately 50 at\%.We also estimate the atomic composition ratio of $\mathrm{Sb} /(\mathrm{Sb}+\mathrm{Te})$ in Fig. 3(b). The atomic composition ratio is almost constant at the stoichiometric proportion when the annealing temperature is less than $250^{\circ} \mathrm{C}$. As the annealing temperature increases, atomic composition ratio gradually decreases. This might be because antimony atoms evaporate in the flow gas or because antimony in the thin film diffuses back into the substrate.

Figure4 showsthe XRD patterns of antimony telluride thin films annealed at different temperatures. We observe four small peaks corresponding to antimony telluride $\left(\mathrm{Sb}_{2} \mathrm{Te}_{3}\right)$ in the as-deposited thin film, indicating that the thin film had low crystallinity.The crystallinity improveswhen the thin film is 
annealed at $200^{\circ} \mathrm{C}$. The main peaks are $\left(\begin{array}{lll}0 & 1 & 5\end{array}\right),\left(\begin{array}{lll}1 & 0 & 10\end{array}\right)$ and $\left(\begin{array}{lll}1 & 1 & 0\end{array}\right)$. We do not observe $c$-axis oriented peaks $\left(\begin{array}{lll}0 & 0 & 1\end{array}\right)$.The $\mathrm{XRD}$ pattern of the thin film annealed at $250^{\circ} \mathrm{C}$ is similar to that of the thin film annealed at $200^{\circ} \mathrm{C}$. At $300^{\circ} \mathrm{C}$, peaks originating fromthe impuritiesin the substrate begin to appear. The XRD peaks from impuritiesare clearly observed at the annealing temperature of $350^{\circ} \mathrm{C}$, but the $\mathrm{Sb}_{2} \mathrm{Te}_{3}$ crystal structure remains unchanged. When the annealing temperature is increased to $400^{\circ} \mathrm{C}$, the $\mathrm{XRD}$ pattern drastically changes. We do not observe the crystalline peaks from $\mathrm{Sb}_{2} \mathrm{Te}_{3}$. All the observed peaks are derived from other chemical compounds combining the elements of the thin film, the substrate and chromium oxide. Therefore, we concluded that the crystal structure of $\mathrm{Sb}_{2} \mathrm{Te}_{3}$ wasnot maintained when a large amount of impurities (50 at\%) were present. This transformation of the XRD patterns between $350^{\circ} \mathrm{C}$ and $400^{\circ} \mathrm{C}$ corresponds to the change in surface morphology over the same temperature range(Figs. 2(e) and 2(f)).

To further investigate the crystallographic properties of the antimony telluride thin films, we analyzed the XRD patterns in detail, as shown in Fig. 5. The average crystallite size was estimated from the full width at half maximum of the XRD peak $\left(\begin{array}{lll}0 & 1 & 5\end{array}\right)$ using Scherrer's equation.We do not estimate the crystallite size of the thin film annealed at $400^{\circ} \mathrm{C}$ because the XRD peaks from the $\mathrm{Sb}_{2} \mathrm{Te}_{3}$ crystal structure are not observed in this sample.The average crystallite size dependence onannealing temperature is shown in Fig. 5(a). The crystallite size of the as-deposited thin film is approximately 10 $\mathrm{nm}$. According to the SEM image of the as-deposited thin film in Fig. 2(a), the size of spherical-shaped grains was approximately $1 \mu \mathrm{m}$, indicating that the spherical-shaped grains are polycrystalline. The thin 
film annealed at $200^{\circ} \mathrm{C}$ exhibits crystallites of approximately $50 \mathrm{~nm}$ in size, which is 5 times larger than that of the as-deposited thin film. With further increases in the annealing temperature, the crystallite size increases linearly. Finally, the average crystallite size in the thin film reaches $60 \mathrm{~nm}$ at an annealing temperature of $350^{\circ} \mathrm{C}$. Even though the crystallite size increaseswith annealing temperature, the crystallite size is always smaller than the grain size observed by SEM. Therefore, the grains of the thin films remain polycrystalline even after thermal annealing at $350^{\circ} \mathrm{C}$.

The XRD intensity ratio was estimated by the peak intensity ratio of the $\left(\begin{array}{lll}0 & 1 & 5\end{array}\right)$ peak to the sum of all the peaks, $\Sigma(h k l)$, as shown in Fig. 5(b). The XRD intensity ratio of the thin films stays approximately constant at 0.5 for annealing temperaturesbelow $250^{\circ} \mathrm{C}$. As the annealing temperature increases further, the XRD intensity ratio gradually decreases. This indicates that the crystal structure changes gradually due to diffusion of impurities from the substrate.

\subsection{Thermoelectric properties of antimony telluride thin films}

Figure6 shows the relationship between the annealing temperature and in-plane thermoelectric properties (Seebeck coefficient, electrical conductivity, and power factor) of the antimonytelluride thin films. In Fig. 6(a), the as-deposited thin film and the thin film annealed at $200^{\circ} \mathrm{C}$ demonstrate a relatively high Seebeck coefficient of approximately $170 \mu \mathrm{V} / \mathrm{K}$. In general, antimony telluride alloysexhibit a high Seebeck coefficient at stoichiometric atomic composition[4], and sothe results of these two samples are consistent with this general phenomena. As the annealing temperature increases, 
the Seebeck coefficient decreases. This trend is consistent with those of the atomic composition ratio and XRD intensity ratio. The Seebeck coefficient of the thin film annealed at $350^{\circ} \mathrm{C}$ is $66 \mu \mathrm{V} / \mathrm{K}$.At the annealing temperature of $400^{\circ} \mathrm{C}$, the Seebeck coefficient exhibits a value of $-37 \mu \mathrm{V} / \mathrm{K}$, indicating that the thin film has become an $n$-type semiconducting material. This is because the $\mathrm{Sb}_{2} \mathrm{Te}_{3}$ crystal structure does not existin the thin film at this annealing temperature.

In Fig. 6(b), theas-deposited thin film possessesvery low electrical conductivity,possibly because this film obtains the lower mobility owing to the low crystallinity and the small crystallite size, whereas the carrier concentration is suitable value leading to the high Seebeck coefficient. The electrical conductivity rapidly increases between the annealing temperatures 200 to $300^{\circ} \mathrm{C}$. The thin film annealed at $300^{\circ} \mathrm{C}$ exhibits the maximum electrical conductivity of $1034 \mathrm{~S} / \mathrm{cm}$. This rapid increase in electrical conductivity is due to improving the crystallinity and increasingthe carrier concentration induced by the impurity contamination. At the annealing temperature of $350^{\circ} \mathrm{C}$, the electrical conductivity rapidly decreases,possibly becausethe gaps between the grains increase, as shown in Fig. 2(e).Finally, the lowest electrical conductivity is observed forthe thin film annealed at $400^{\circ} \mathrm{C}$ because of the porous structure, as shown in Fig. 2(f).

We calculated the power factor by using the measured Seebeck coefficient and electrical conductivity, as shown in Fig. 6(c). The dependence of power factor on annealing temperature shows a similar trend as that of electrical conductivity. We obtain antimony telluride thin films with higher thermoelectric performance at the annealing temperatures of $250^{\circ} \mathrm{C}$ and $300^{\circ} \mathrm{C}$. The thin film annealed at $300^{\circ} \mathrm{C}$ 
exhibits the maximum power factor of $13.6 \mu \mathrm{W} /\left(\mathrm{cm} \cdot \mathrm{K}^{2}\right)$. As mentioned above, the thin films annealed at $300^{\circ} \mathrm{C}$ contain a certain amount of impurities from the substrate. We concluded that the impurities contribute to the decrease in Seebeck coefficient as well as to the increase in electrical conductivity, with the contribution to the enhancement in electrical conductivity surpassing that of the decrease in the Seebeck coefficient.Finally, the maximum power factor reported here is one of the excellent results,comparedto that of bismuth telluride-based alloy thin films prepared by electrodeposition[16-18].Although we achieve higher thermoelectric performance by using an optimized annealing treatment, there is still room for improvement to avoid the impurity diffusion from the substrate. One strategy is to forma diffusion barrier layer on the substrate surface prior to $\mathrm{Sb}_{2} \mathrm{Te}_{3}$ depostion[34,35].

\section{Conclusions}

We investigate the effect of thermal annealing on thestructural and thermoelectric properties of p-type antimony telluride thin films on a stainless steel (SUS304) substrate by electrodeposition. Prior to the thin film deposition, we performed CV analysis to determine the appropriate potential. As a result, we found thatthe appropriate applied potential for the film deposition was $-0.1 \mathrm{~V}$. For thermal annealing of the antimony telluride thin films, we varied the annealing temperatures from 200 to $400^{\circ} \mathrm{C}$, and fixed annealing time at $1 \mathrm{~h}$. We observed that the as-deposited thin film and the thin films annealed at temperatures less than $250^{\circ} \mathrm{Cproduced}$ stoichiometric atomic composition $(\mathrm{Sb}: \mathrm{Te}=40: 60)$ and 
contained no impurities from the substrate. The electrical conductivity of the as-deposited thin film was relatively low because of a low degree of crystallinity. At the annealing temperature $300^{\circ} \mathrm{C}$, we observed a certain amount of impurities $(\mathrm{Fe}, \mathrm{Cr}, \mathrm{Ni})$ in the thin film. The Seebeck coefficient was decreased but the electrical conductivity was increased at this annealing temperature. The thin film obtained a maximum power factor of $13.6 \mu \mathrm{W} /\left(\mathrm{cm} \cdot \mathrm{K}^{2}\right)$. This maximum power factor is one of the excellentresults, comparable to that of bismuth telluride-based alloy thin films prepared by electrodeposition. Further increasing the annealing temperature to $400^{\circ} \mathrm{C}$ drastically changed the film structureand thermoelectric properties. The impurity concentration in the film reached approximately 50 at $\%$. The crystal structure of $\mathrm{Sb}_{2} \mathrm{Te}_{3}$ completely disappeared, and otheralloysoriginating from combing elements from the thin film and the substrate were observed. Finally, although we achieved higher thermoelectric performance by using an optimized annealing treatment,further improvementscan be obtained by avoidingcontamination from the substrate.

\section{Acknowledgments}

The authors wish to thank Y. Miyamoto, H. Kiyuna, M. Okuhata, K. Wada, J. Hamadaand S. Morikawaat Tokai University for their experimental support. This researchwas financially supported by Japan Science and Technology Agency (JST). 


\section{References}

[1]J.A.Paradiso, T.Starner, Energy scavenging for mobile and wireless electronics,IEEE Pervasive Comput. 4 (2005) 18-27.

[2]S.H. Nicholas, G.A.Glenn, Small-scale energy harvesting through thermoelectric, vibration, and radiofrequency power conversion,J. Appl. Phys.103 (2008) 101301.

[3]M.Takashiri, T.Shirakawa, K. Miyazaki, H.Tsukamoto, Fabrication and characterization of bismuth-telluride-based alloy thin film thermoelectric generators by a flash evaporation method,Sens. Actuators, A 138 (2007) 329-334.

[4]D.M. Rowe, CRC Handbook of Thermoelectrics, CRC, London, 1995, Section D.

[5]H.Zou, D.M.Rowe, S.G.K.Williams, Peltier effect in a co-evaporated $\mathrm{Sb}_{2} \mathrm{Te}_{3}(\mathrm{P})-\mathrm{Bi}_{2} \mathrm{Te}_{3}(\mathrm{~N})$ thin film thermocouple, Thin Solid Films408 (2002)270-274.

[6]J.Dheepa, R.Sathyamoorthy, S.Velumani, A.Subbarayan, K.Natarajan, P.J.Sebastian, Electrical resistivity of thermally evaporated bismuth telluride thin films,Sol. Energy Mater. Sol. Cells 81 (2004) 305-312.

[7]M.Takashiri, S.Tanaka, H.Hagino, K.Miyazaki, Strain and Grain Size Effects on Thermal Transport in Highly-Oriented Nanocrystalline Bismuth Antimony Telluride Thin Films,Int. J. Heat Mass Transfer 76 (2014) 376-384.

[8]H.Bottner, A.Schubert, K.H.Schlereth, D.Eberhard, A.Gavrikov, M.Jagle, G.Kuhner, C.Kunzel, J.Nurnus, G.Plescher, New Thermoelectric Components using Microsystem Technologies,J. 
Microelectromech. Syst.13 (2004)414-420.

[9]H.Huang, W.L.Luan, S.T.Tu, Influence of annealing on thermoelectric properties of bismuth telluride films grown via radio frequency magnetron sputtering, Thin Solid Films517 (2009) 3731-3734.

[10]K.Kusagaya, M.Takashiri, Investigation of the effects of compressive and tensile strain on n-type bismuth telluride and p-type antimony telluride nanocrystalline thin films for use in flexible thermoelectric generators,J. Alloys Compd. 653 (2015) 480-485.

[11]G.J.Snyder, J.R. Lim, C.K. Huang, J.P.Fleurial, Thermoelectric microdevice fabricated by a MEMS-like electrochemical process,Nat. Mater. 2 (2003) 528-531.

[12]S. Li, M.S. Toprak, H.M. Soliman, J. Zhou, M. Muhammed, D. Platzek, E.Muller, Fabrication of Nanostructured Thermoelectric Bismuth Telluride Thick Films by Electrochemical Deposition,Chem. Mater.18 (2006) 3627-3633.

[13]K. Matsuoka, M. Okuhata, N. Hatsuta, M.Takashiri, Effect of composition on the properties of bismuth telluride thin films produced by galvanostatic electrodeposition. Trans,Mater. Res. Soc. Jpn40 (2015) 373-377.

[14]M. Takahashi, Y. Katou, K. Nagata, S.Furuta, The composition and conductivity of electrodeposited Bi-Te alloy films, Thin Solid Films240(1994) 70-72.

[15]M.S. Martin-Gonzalez, A.L. Prieto, R. Gronsky, T. Sands, A.M.Stacy, Insights into the electrodeposition of $\mathrm{Bi}_{2} \mathrm{Te}_{3}$,J. Electrochem. Soc.149(2002) 546-554.

[16]C.Boulanger, Thermoelectric Material Electroplating: a Historical Review,J. Electron. Mater. 39 
(2010) 1818-1827.

[17]F. Xiao, C. Hangarter, B. Yoo, Y. Rheem, K.H. Lee, N.V. Myung, Recent progress in electrodeposition of thermoelectric thin films and nanostructures,Electrochim. Acta53 (2008) $8103-8117$.

[18]R. Rostek, N.Stein, C.Boulanger, A review of electroplating for V-VI thermoelectric films: From synthesis to device integration,J. Mater. Res.30 (2015) 2518-2543.

[19]M. Takashiri,S. Tanaka, K.Miyazaki, Determination of the origin of crystal orientation for nanocrystalline bismuth telluride-based thin films prepared by use of the flash evaporation method,J. Electron. Mater.43(2014) 1881-1889.

[20]M. Takashiri, K. Imai, M. Uyama, H. Hagino, S. Tanaka, K. Miyazaki, Y.Nishi, Effects of homogeneous irradiation of electron beam on crystal growth and thermoelectric properties of nanocrystalline bismuth selenium telluride thin films. J. Alloys Compd.612(2014) 98-102.

[21]M. Takashiri, K. Imai, M. Uyama, H. Hagino, S. Tanaka, K. Miyazaki, Y.Nishi, Comparison of crystal growth and thermoelectric properties of n-type Bi-Se-Te and p-type Bi-Sb-Tenanocrystalline thin films: Effects of homogeneous irradiation with an electron beam,J. Appl. Phys.115(2014) 214311.

[22]M. Takashiri, K. Kurita, H. Hagino, S. Tanaka,K. Miyazaki, Enhanced thermoelectric properties of phase-separating bismuth selenium telluride thin films via a two-step method,J. Appl. Phys.118(2015) 065301. 
[23]R. Lechner,H.Wiggers,A. Ebbers,J.Steiger,M.S. Brandt,M.Stutzmann, Thermoelectric effect in laser annealed printednanocrystalline silicon layers,Phys. Status Solidi RRL1(2007) 262-264.

[24]W.J.Baumgardner,J.J. Choi,K.Bian,K.L. Fitting,D.M.Smilgies,M.O. Thompson, T.Hanrath, Pulsed laser annealing of thin films of self-assembled nanocrystals,ACS Nano5 (2011) 7010-7019.

[25]D.H. Kim, G.H.Lee, Effect of rapid thermal annealing on thermoelectric properties of bismuth telluride films grown by co-sputtering,Mater. Sci. Eng., B131 (2006) 106-110.

[26]L.S. Faraji,R.P. Singh, M.Allahkarami, Pulsed laser deposition of bismuth telluride thin film and annealing effects, Eur. Phys.J. Appl. Phys.46 (2009) 20501.

[27]X. Duan, Y.Jiang, Annealing effects on the structural and electrical transport properties of n-type $\mathrm{Bi}_{2} \mathrm{Te}_{2.7} \mathrm{Se}_{0.3}$ thin films deposited by flash evaporation,Appl. Surf. Sci.256 (2010) 7365-7370.

[28] M.Y. Kim,T.S. Oh, Crystallization Behavior and Thermoelectric Characteristics of the Electrodeposited $\mathrm{Sb}_{2} \mathrm{Te}_{3}$ Thin Films, Thin Solid Films518 (2010) 6550-6553.

[29]C. Schumacher,K.G.Reinsberg, R. Rostek,L.Akinsinde,S.Baessler,S.Zastrow,G.Rampelberg, P. Woias,C.Detavernier,J.A.C.Broekaert, J. Bachmann,K.Nielsch, Optimizations of pulsed plated p and n-type $\mathrm{Bi}_{2} \mathrm{Te}_{3}$-based ternary compounds by annealing in different ambient atmospheres, Adv. Energy Mater.3 (2013) 95-104.

[30]C.Schumacher,K.G.Reinsberg,L.Akinsinde,S.Zastrow,S.Heiderich,W.Toellner,G.Rampelberg,C.Det avernier,J.A.C.Broekaert,K.Nielsch,J. Bachmann, Optimization of Electrodeposited $\mathrm{p} \square$ Doped $\mathrm{Sb}_{2} \mathrm{Te}_{3}$ Thermoelectric Films by Millisecond Potentiostatic Pulses,Adv. Energy Mater. 2 (2012) 
$345-352$.

[31]H.H. Huang,M.P. Lu, C.H. Chiu,L.C. Su,C.N. Liao,J.Y. Huang,H.L. Hsieh, Enhanced Seebeck coefficient of bismuth telluride compounds with graded doping profiles,Appl. Phys. Lett. 103 (2013) 163903.

[32]J. Kuleshova,E.Koukharenko,X. Li,N.Frety,I.S.Nandhakumar,J. Tudor,P.B. Steve,N.M. White, Optimization of the Electrodeposition Process of High-Performance Bismuth Antimony Telluride Compounds for Thermoelectric Applications,Langmuir26 (2010) 16980-16985.

[33]G. Leimkühler,I.Kerkamm,R.Reineke-Koch, Electrodeposition of Antimony Telluride,J. Electrochem. Soc. 149 (2002) C474-C478.

[34]J.Liu,Q. Gong,Y. Shao,D. Zhuang,J. Liang, In-situ fabrication of $\mathrm{MoSi}_{2} / \mathrm{SiC}^{-} \mathrm{Mo}_{2} \mathrm{C}$ gradient anti-oxidation coating on Mo substrate and the crucial effect of $\mathrm{Mo}_{2} \mathrm{C}$ barrier layer at high temperature,Appl. Surf. Sci. 308 (2014) 261-268.

[35]X.C. Fan,M.Gu,X. Shi,L.D. Chen,S.Q. Bai,R.Nunna, Fabrication and reliability evaluation of $\mathrm{Yb}_{0.3} \mathrm{Co}_{4} \mathrm{Sb}_{12} / \mathrm{Mo}-\mathrm{Ti} / \mathrm{Mo}-\mathrm{Cu} / \mathrm{Ni}$ thermoelectric joints,Ceram. Int.41 (2015) 7590-7595. 


\section{Figure captions}

Figure 1. Cyclic voltammetry scan of the $\mathrm{Sb} / \mathrm{Te}$ electrolyte recorded at RT and a scan rate of $5 \mathrm{mV} / \mathrm{s}$.

Figure 2. SEM imagesof the surface morphology and grain structure of the antimony telluride thin

filmsannealed at (a) RT(as-deposited), (b) $200^{\circ} \mathrm{C}$, (c) $250^{\circ} \mathrm{C}$, (d) $300^{\circ} \mathrm{C}$, (e) $350^{\circ} \mathrm{C}$, and (f)

$400^{\circ} \mathrm{C}$.

Figure 3. Annealing temperature dependence of (a) the atomic composition and (b) the atomic composition ratio, $\mathrm{Sb} /(\mathrm{Sb}+\mathrm{Te})$ of antimony telluride thin films determined by EPMA.

Figure 4. X-ray diffraction patterns of antimony telluride thin films at various annealing temperatures.

The peaks indicated by the solid circles, squares, open circles, triangles, and diamondscorrespond to the chemical compounds obtained by alloying the elements of the thin film and the substrate.

Figure 5. Annealing temperature dependence of (a) the average crystallite size and (b) the XRD intensity ratio of antimony telluride thin films.

Figure 6. Annealing temperature dependence of (a) the Seebeck coefficient, (b) the electrical conductivity, and (c) the power factor of antimony telluride thin films. 


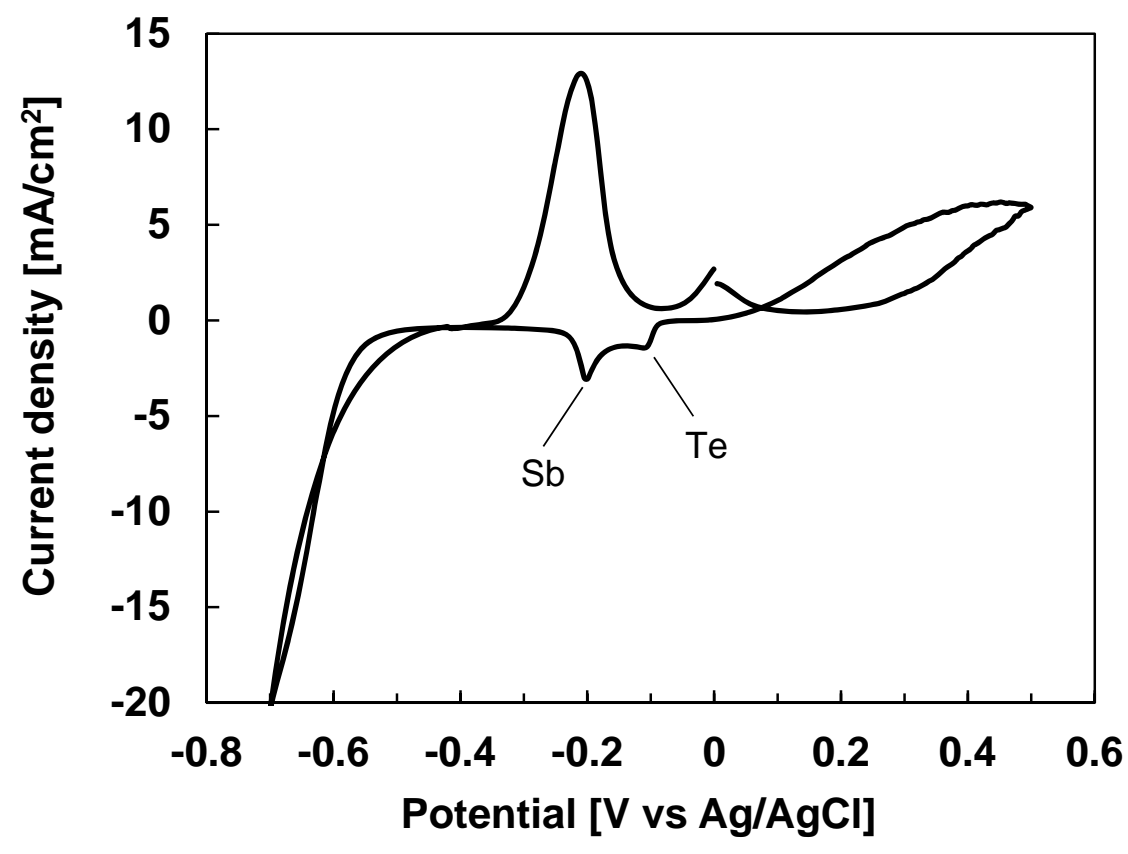

Figure 1 

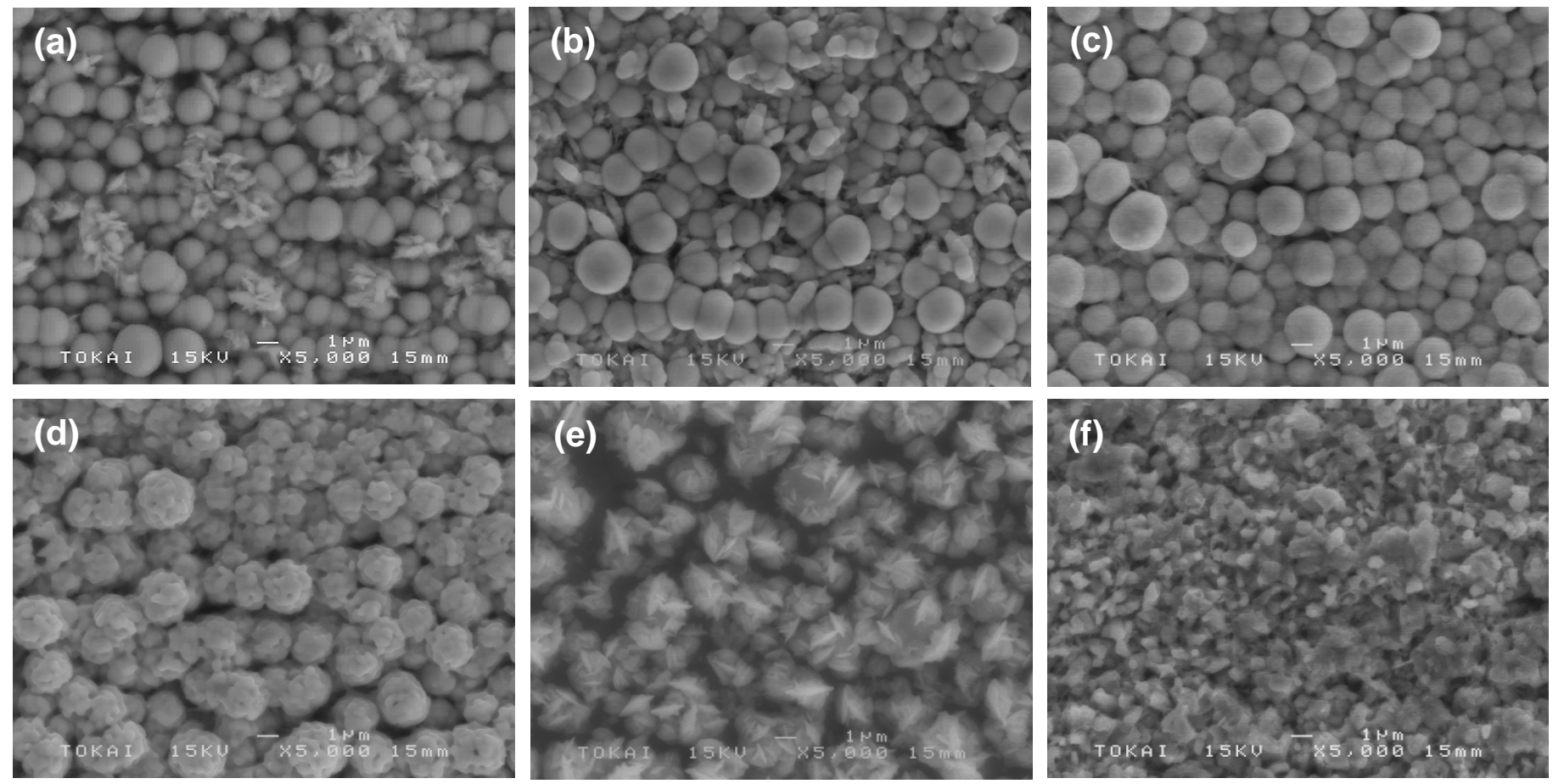

Figure 2 

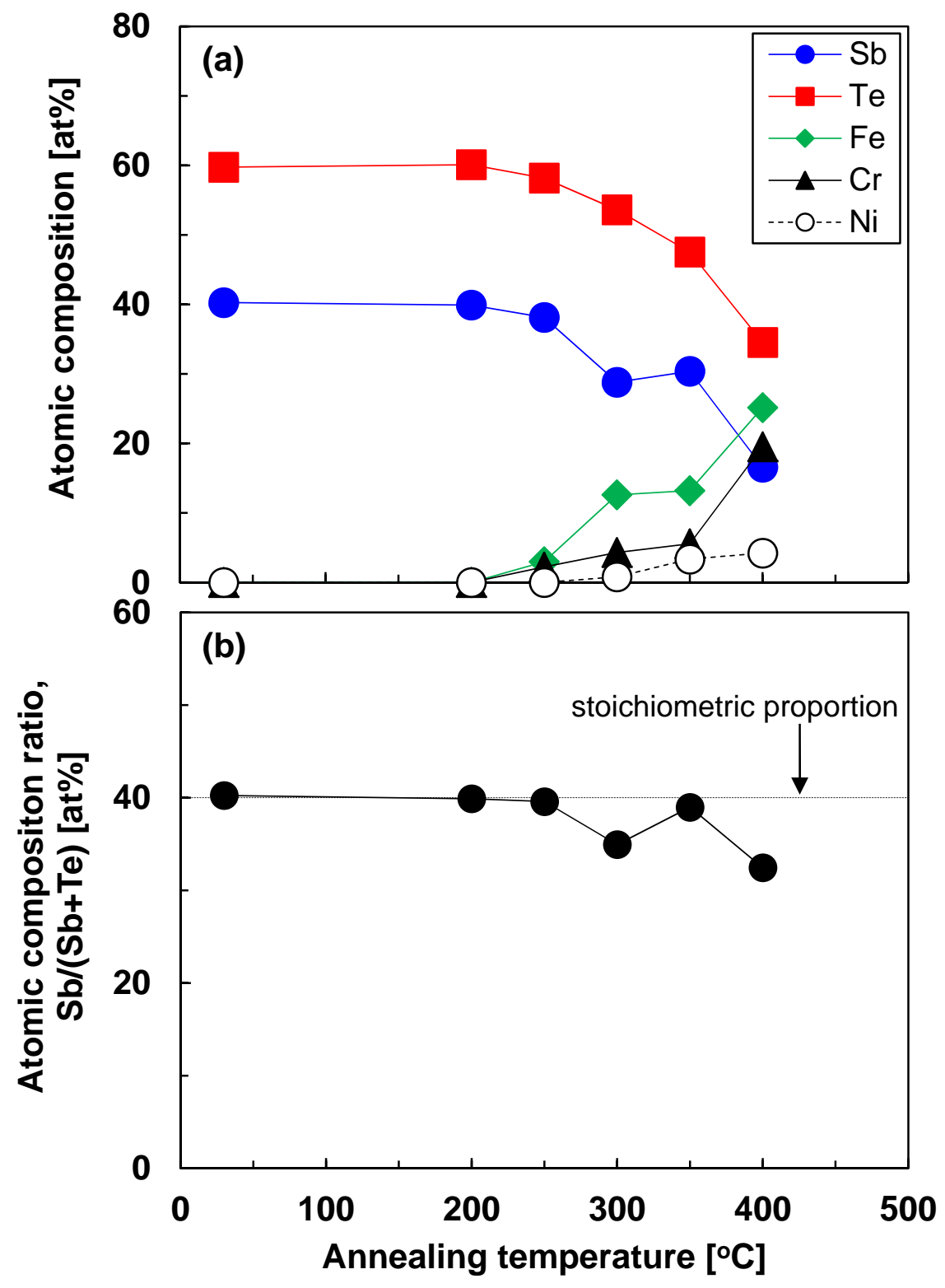

Figure 3 


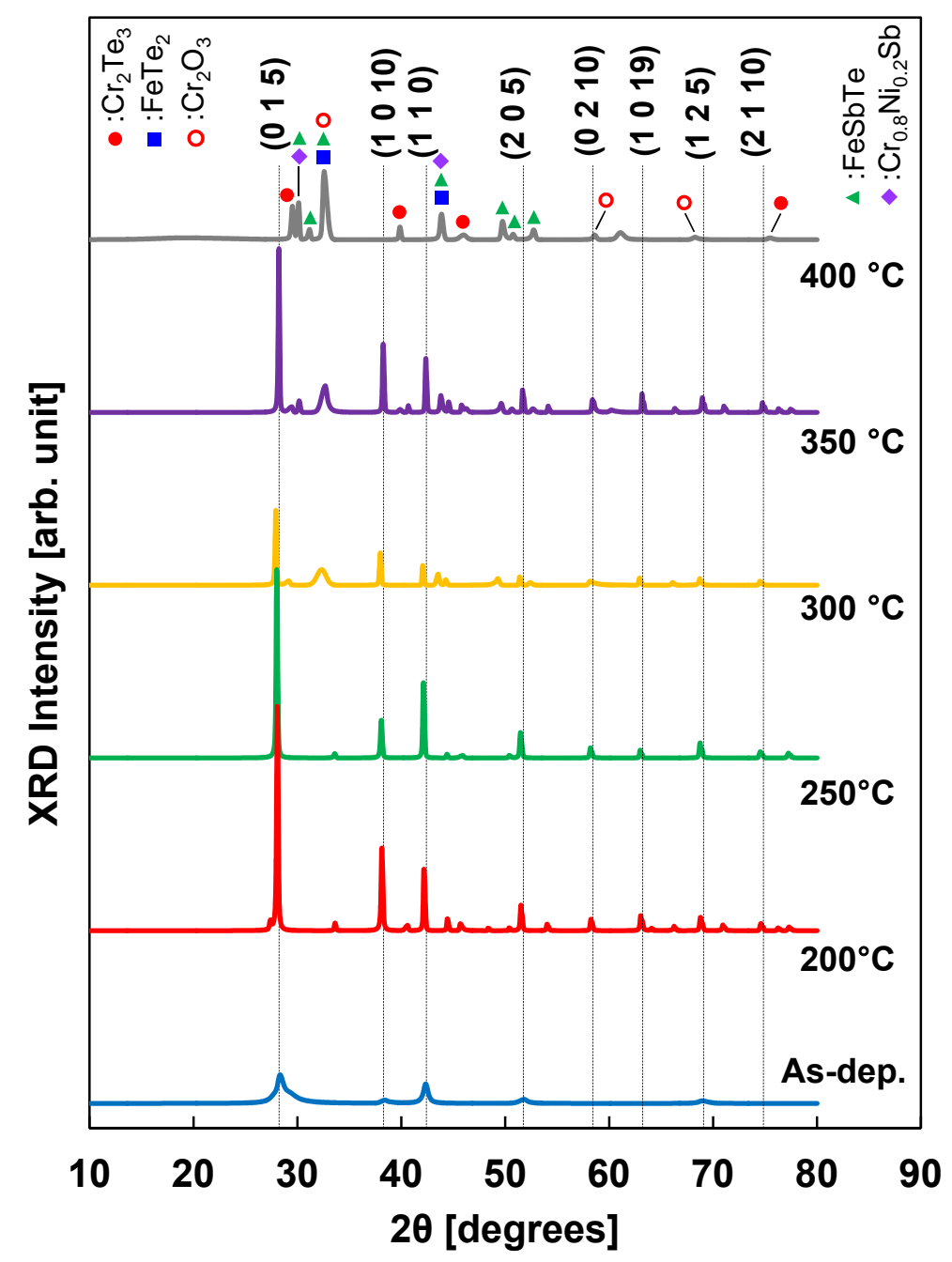

Figure 4 

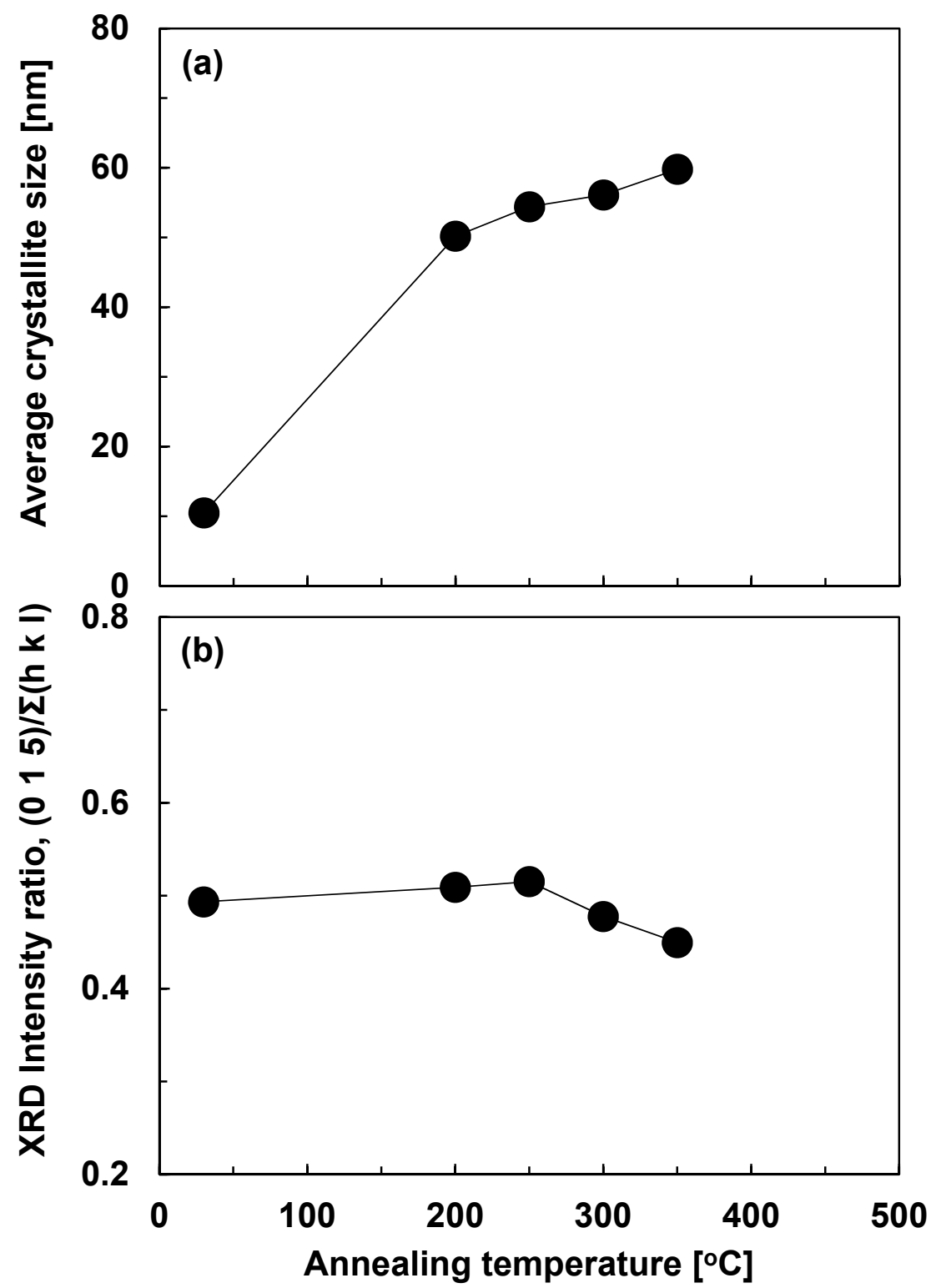

Figure 5 

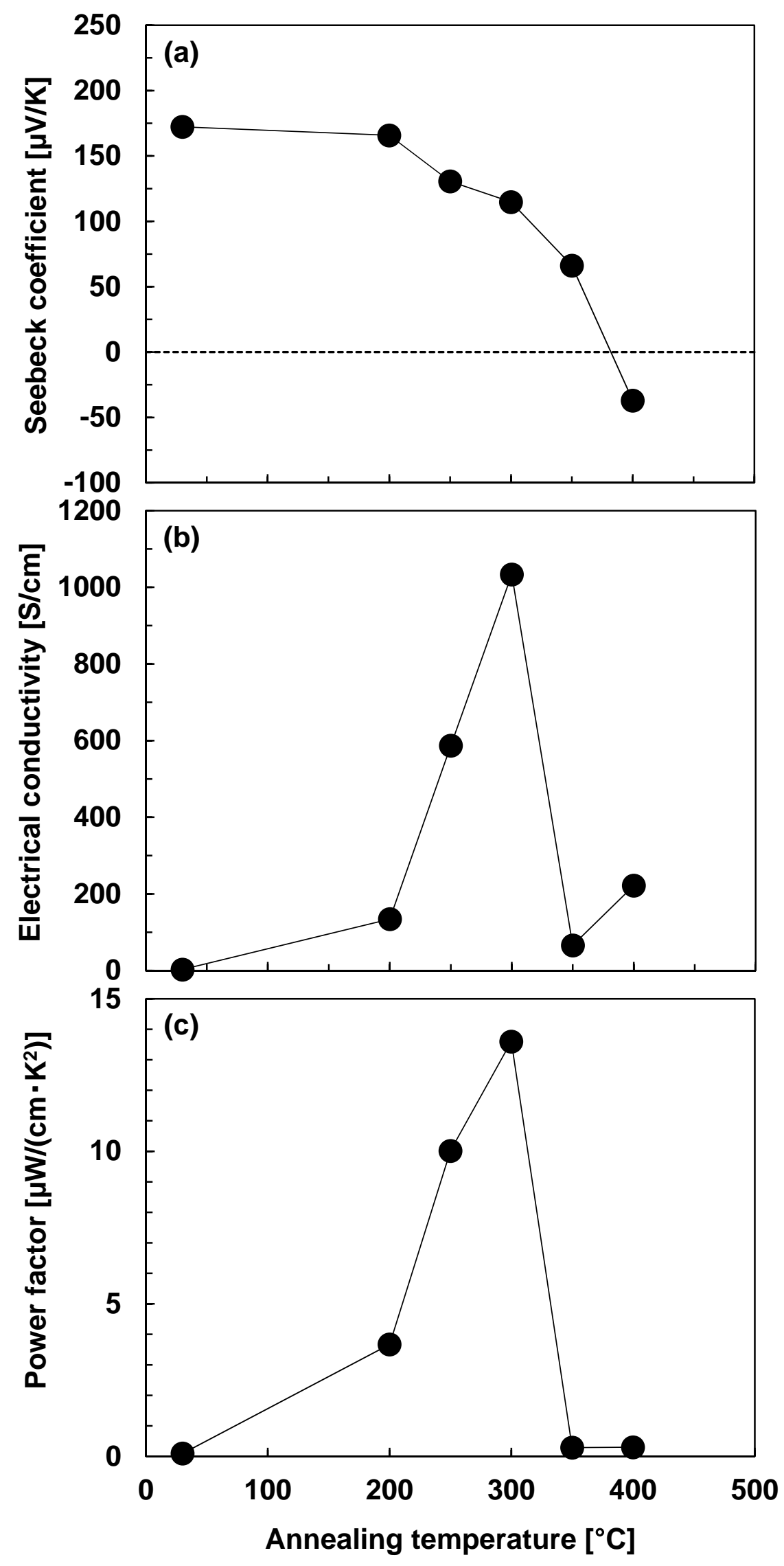

Figure 6 